\title{
Influence of the cross-section shape on the lateral torsional buckling capacity
}

\author{
D. Djurić-Mijović \& M. Trajković \\ Faculty of Civil Engineering and Architecture, University of Niš, \\ Republic of Serbia
}

\begin{abstract}
The bifurcation-load of a bending girder, the ideal lateral torsional buckling moment $\mathrm{M}_{\mathrm{KI}}$, is of great importance for the verification of stability. The solutions in the literature exist almost exclusively for double-symmetrical cross sections. The whole problem considering the lateral torsional buckling is quite complex as the analytical solutions for determining the lateral torsional buckling strength exist in closed-form only for the most simple cases, e.g. for the case of a simply supported double symmetric beam of a constant cross-section under uniform moment. However, for most cases, in order to obtain the buckling load, numerical or approximate solutions are required. This article examines the problem of elastic lateral torsional bucking of simply supported, monosymmetric $\mathrm{I}$ and T-beams under two different transverse load cases. Correct and approximate Euro Code 3 (EC3) approaches for obtaining elastic lateral torsional buckling capacities of monosymmetric I and T-beams were investigated for each load case. Solutions were obtained in terms of the easily evaluated degree of beam monosymmetry, $\beta_{\mathrm{f}}$, beam parameter, $\overline{\mathrm{K}}$, and monosymmetry parameter, $\mathrm{r}_{\mathrm{z}}$. The results obtained are graphically presented and compared. It was found that approximation formulae for $\mathrm{r}_{\mathrm{z}}$ given by Kitipornchai and Trahair are much more accurate compared to the correct formulae than the approximation formulae proposed by EC3. T-beams are considered as a special case of monosymmetric I cross sections. In conclusion, the authors recommend utilisation of different types of cross sections for different types of loading and length of the beams. The result can be significant savings in material as well as increased stability of the structure regarding lateral torsional buckling of monosymmetric cross section girders.

Keywords: lateral torsional buckling, monosymmetric cross section, EC3, thinwalled open cross section, monosymmetry parameter.
\end{abstract}




\section{Lateral torsional buckling}

Lateral torsional buckling is a mode of structural failure in which one or more members (beams, trusses....) of a frame suddenly deflect and twist out of the plane of loading (Trahair [2]). If it is not prevented in the right way, lateral torsional buckling may reduce the load-carrying-capacity of the structure because members subjected to a flexure have much greater strength and stiffness in the plane of the loading (major principal axis) than in the minor principal axis. The implication is that structural members are subjected to a failure by lateral torsional buckling before they even reach their full in-plane capacity.

This problem is frequent and it is perceived at slender members or structures, and so, of great importance in the design of steel structures. Also, it often occurs in the construction phase. This kind of structure deformation does not concern only individual members, but also occurs in rigid-jointed structures, where continuity of rotations between adjacent members causes them to interact during buckling.

Lateral torsional buckling of a member, as a combination of lateral buckling and torsional buckling, is a case in which transverse displacements of a member, out-of-plane deflection $\mathbf{v}$ and in-plane deflection $\mathbf{w}$, occur in combination with rotation $\vartheta$, around its major axis.

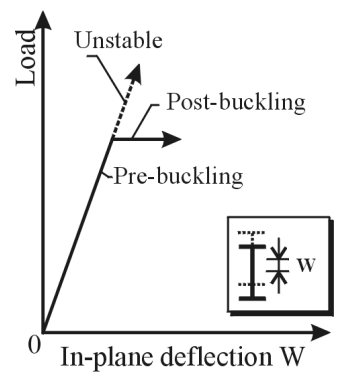

(a) In-Plane Bending

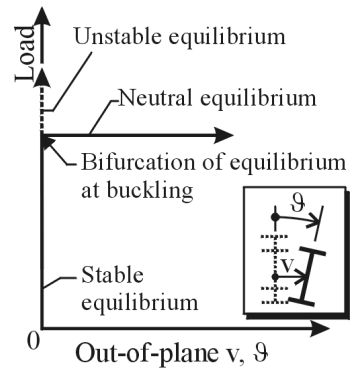

(b) Out-of-plane buckling

Figure 1: Elastic bending and buckling.

A beam, which is bent in its stiffer principal plane, may buckle out of that plane by deflecting laterally out-of-plane v and rotating (twisting) $\vartheta$, as shown in the Figure 1(b). These deformations are interdependent. For example, a twist rotation $\vartheta$ of the beam will cause the in-plane bending moment $M_{y}$ to have an out-plane component $\mathrm{M}_{\mathrm{y}} \vartheta$ as shown in Figure 2(a), which will cause lateral deflections v. Conversely, lateral deflections $\mathrm{v}$ will cause the moment $\mathrm{M}_{\mathrm{y}}$ to have a torque component $\mathrm{M}_{\mathrm{y}} \mathrm{v}^{\prime}$ as shown in Figure 2(b), which will cause twist rotations $\vartheta$.

Lateral torsional buckling is resisted by combinations of the bending resistances $E I_{z} d^{2} v / d x^{2}$ and $-E I_{y} d^{2} w / d x^{2}$ and the torsional resistances $G_{t} d \vartheta / d x$ and $-\mathrm{EI}_{\mathrm{w}} \mathrm{d}^{3} \mathrm{~g} / \mathrm{dx}^{3}$ (Trahair [2]). 


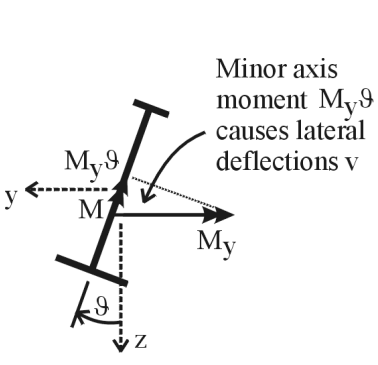

(a) Out-of-Plane Moment

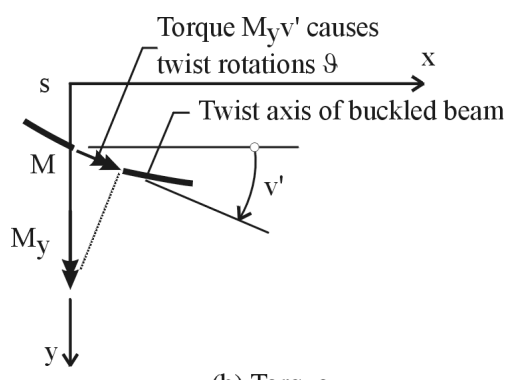

(b) Torque

Figure 2: $\quad$ Interdependence of $\mathrm{v}$ and $\vartheta$.

\section{Buckling capacities of monosymmetric I-cross sections}

\subsection{Description of the system, boundary conditions and load cases}

In this paper the single span beams, simply supported in-plane $\left(\mathrm{w}_{0}=\mathrm{w}_{\mathrm{L}}=0, \mathrm{w}_{0}^{\prime}, \mathrm{w}_{\mathrm{L}}^{\prime} \neq 0\right.$, ) and simply supported out-of-plane are considered. The ends of the beams, that are simply supported out-of-plane, are fixed against out-of-plane deflections and twist rotations $\mathrm{v}_{0}=\mathrm{v}_{\mathrm{L}}=\vartheta_{0}=\vartheta_{\mathrm{L}}=0$, but are unrestrained against minor axis rotations $\mathrm{v}_{0}^{\prime}, \mathrm{v}_{\mathrm{L}}^{\prime}\left(\right.$ so that $\mathrm{v}_{0}^{\prime \prime}=\mathrm{v}_{\mathrm{L}}^{\prime \prime}=0$ ) and against warping displacements proportional to $\vartheta_{0}^{\prime}, \vartheta_{\mathrm{L}}^{\prime}$ (so that $\vartheta_{0}^{\prime \prime}=\vartheta_{\mathrm{L}}^{\prime \prime}=0$ ), Figure 3(c).

The beams are assumed to be perfectly straight and untwisted before loading and are exposed to the loads that initially cause deflections only in the plane of loading. It is also assumed that the direction of the load remains unchanged during buckling.

Within this paper the central concentrated load, Figure 3(a) and uniformly distributed load case, Figure 3(b) were examined.

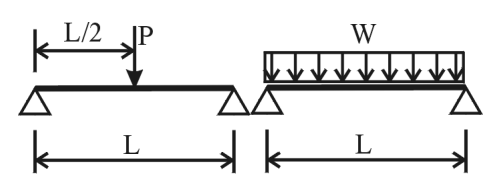

(a)

(b)
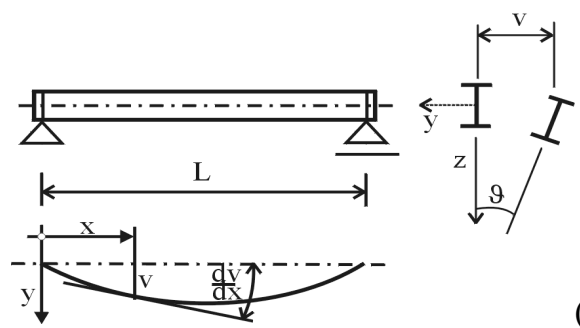

Figure 3: $\quad$ System, boundary conditions and load cases.

\subsection{Differential equations}

Differential equilibrium equations (Trahair [2]) for a simply supported beam with monosymmetric cross-section under a uniform moment induced by equal and opposite end moments $\mathrm{M}$, are shown in Figure 4. 


$$
\begin{gathered}
\left(\mathrm{EI}_{\mathrm{z}} \mathrm{v}^{\prime \prime}\right)^{\prime \prime}+\left(\mathrm{M}_{\mathrm{y}} \vartheta\right)^{\prime \prime}=0 \\
\left(\mathrm{EI}_{\mathrm{w}} \vartheta^{\prime \prime}\right)^{\prime \prime}-\left(\mathrm{GI}_{\mathrm{t}} \vartheta^{\prime}\right)^{\prime}+\mathrm{M}_{\mathrm{y}} \mathrm{v}^{\prime \prime}-\left(\mathrm{M}_{\mathrm{y}} \mathrm{r}_{\mathrm{z}} \vartheta^{\prime}\right)^{\prime}=0
\end{gathered}
$$

with the boundary conditions:

$$
\begin{aligned}
& \mathrm{v}_{0, \mathrm{~L}}=\mathrm{v}_{0, \mathrm{~L}}^{\prime \prime}=\vartheta_{0, \mathrm{~L}}=\vartheta_{0, \mathrm{~L}}^{\prime \prime}=0
\end{aligned}
$$

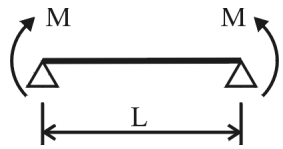

Figure 4: $\quad$ Simply supported beam under end moments.

Terms $\left(\mathrm{M}_{\mathrm{y}} \mathrm{r}_{\mathrm{z}} \vartheta^{\prime}\right)^{\prime}$ are associated with the monosymmetry property $\mathrm{r}_{\mathrm{z}}$, called the monosymmetry parameter of the cross section or "Wagner effect", which is given by

$$
r_{z}=\frac{1}{I_{y}} \int_{A} z\left(y^{2}+z^{2}\right) d A-2 z_{S}
$$

$\mathrm{Z}_{\mathrm{S}}$ is the distance between the centroid and shear centre and $\mathrm{I}_{\mathrm{y}}$ is the major axis moment of inertia.

Many authors have developed various approximate formulas for $r_{z}$. One of them was developed by Trahair and Kitipornchai (Kitipornchai and Trahair [4])

$$
\mathrm{r}_{\mathrm{Z}} \cong 0.9 \mathrm{~h}_{\mathrm{S}}\left(2 \beta_{\mathrm{f}}-1\right)\left[1-\left(\mathrm{I}_{\mathrm{z}} / \mathrm{I}_{\mathrm{y}}\right)^{2}\right]
$$

in which $\mathrm{I}_{\mathrm{z}} / \mathrm{I}_{\mathrm{y}}$ is the ratio of the second moment of area of the section about minor and major axes respectively, $\mathrm{h}_{\mathrm{s}}$ is the distance between shear centres of the flanges. This formula has very good accuracy and is used for practical purposes.

\subsection{Buckling capacities of monosymmetric I cross-sections}

In the case of double symmetric cross sections the tensile and compressive bending stresses are equal and the flanges are at the same distance from the shear centre. That leads to increasing buckling resistance caused by tensile stresses balanced by increasing buckling action caused by compressive stresses. However, this balance is upset in monosymmetric beams. When such a beam twists during buckling, the longitudinal bending stresses exert a torque around the axis of twist of the member. This torque causes an effective change in the torsional stiffness from $\mathrm{GI}_{\mathrm{t}}$ to $\left(\mathrm{GI}_{\mathrm{t}}+\mathrm{M}_{\mathrm{y}} \mathrm{r}_{\mathrm{z}}\right)$, in which $\mathrm{M}_{\mathrm{y}}$ is the major axis moment and $r_{z}$ is the monosymmetry parameter. As a consequence, when the larger flange is in compression the buckling resistance is increased, and opposite (Anderson and Trahair [5]).

The elastic critical moment, $\mathrm{M}_{\mathrm{KI}}$, of the monosymmetric I-beam under uniform moment is a solution of eqns (1) and (2) and is given as:

$$
\mathrm{M}_{\mathrm{KI}}=\frac{\pi}{\mathrm{L}} \sqrt{\mathrm{EI}_{\mathrm{Z}} \mathrm{GI}_{\mathrm{t}}}\left[\sqrt{1+4 \beta_{\mathrm{f}}\left(1-\beta_{\mathrm{f}}\right) \overline{\mathrm{K}}^{2}+\left(\frac{\mathrm{r}_{\mathrm{z}} \overline{\mathrm{K}}}{\mathrm{h}_{\mathrm{S}}}\right)^{2}}+\frac{\mathrm{r}_{\mathrm{Z}} \overline{\mathrm{K}}}{\mathrm{h}_{\mathrm{S}}}\right]
$$




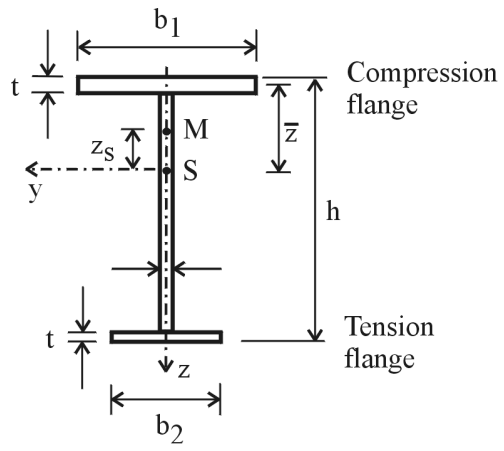

Figure 5: Monosymmetric I-cross sections.

where $\mathrm{EI}_{\mathrm{z}}$ is the minor axis flexural rigidity, $\mathrm{GI}_{\mathrm{t}}$ is the torsional rigidity, $\mathrm{L}$ is the length of the beam. The next parameters are $\overline{\mathrm{K}}$, the beam parameter, also called the torsion parameter and $\beta_{\mathrm{f}}$, the measure of monosymmetry or degree of monosymmetry:

$$
\overline{\mathrm{K}}=\sqrt{\frac{\pi^{2} \mathrm{EI}_{\mathrm{Z}} \mathrm{h}_{\mathrm{S}}{ }^{2}}{4 \mathrm{GI}_{\mathrm{t}} \mathrm{L}^{2}}} ; \quad \beta_{\mathrm{f}}=\frac{\mathrm{I}_{\mathrm{fc}}}{\mathrm{I}_{\mathrm{fc}}+\mathrm{I}_{\mathrm{ft}}} ; 0 \leq \beta_{\mathrm{f}} \leq 1.0
$$

where $h_{s}$ is the distance between shear centres of the flanges. The values of $\bar{K}$ for practical beams are in the range between 0.1 and 2.5 with low values representing long beams and/or compact cross-sections and high values corresponding to short beams and/or slender cross-sections.

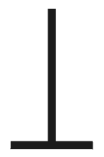

$\beta_{f}=0.0$

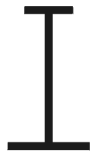

$\beta_{f}=0.1$

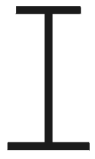

$\beta_{f}=0.3$

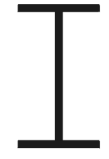

$\beta_{f}=0.5$

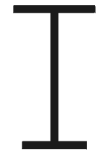

$\beta_{f}=0.7$

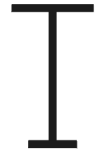

$\beta_{f}=0.9$

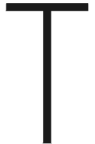

$\beta_{f}=1.0$

Figure 6: Various cross sections depending on $\beta_{f}$.

These two parameters, $\beta_{\mathrm{f}}$ and $\overline{\mathrm{K}}$, enable easily visualization of the monosymmetric I-beam.

\subsection{Euro Code 3 - buckling formulae}

The general formula according to Euro Code 3 for a beam of uniform cross section, elastic critical moment for lateral torsional buckling, $\mathrm{M}_{\mathrm{KI}}$ is given by

$$
\mathrm{M}_{\mathrm{KI}}=\mathrm{C}_{1} \frac{\pi^{2} \mathrm{EI}_{\mathrm{Z}}}{(\mathrm{kL})^{2}}\left\{\left[\left(\frac{\mathrm{k}}{\mathrm{k}_{\mathrm{W}}}\right)^{2} \frac{\mathrm{I}_{\mathrm{W}}}{\mathrm{I}_{\mathrm{Z}}}+\frac{(\mathrm{kL})^{2} \mathrm{GI}_{\mathrm{t}}}{\pi^{2} \mathrm{EI}_{\mathrm{Z}}}+\left(\mathrm{C}_{2} \mathrm{z}_{\mathrm{g}}-\mathrm{C}_{3} \mathrm{z}_{\mathrm{j}}\right)^{2}\right]^{1 / 2}-\left(\mathrm{C}_{2} \mathrm{z}_{\mathrm{g}}-\mathrm{C}_{3} \mathrm{z}_{\mathrm{j}}\right)\right\}
$$


in which $\mathrm{C}_{1}, \mathrm{C}_{2}, \mathrm{C}_{3}$ are factors depending on the loading and boundary conditions, $\mathrm{k}$ and $\mathrm{k}_{\mathrm{w}}$ are effective length factors and these coefficients are given in Annex $\mathrm{F}$ of Euro Code 3.

$$
\mathrm{z}_{\mathrm{g}}=\mathrm{z}_{\mathrm{a}}-\mathrm{z}_{\mathrm{s}} ; \quad \mathrm{z}_{\mathrm{j}}=\mathrm{z}_{\mathrm{s}}-\frac{1}{2 \mathrm{I}_{\mathrm{y}}} \int_{\mathrm{A}} \mathrm{z}\left(\mathrm{y}^{2}+\mathrm{z}^{2}\right) \mathrm{dA}
$$

where $z_{a}$ is the coordinate of the load application point and $z_{s}$ is the coordinate of the shear centre. For an I-section with unequal flanges it is recommended to calculate the warping section constant, $\mathrm{I}_{\mathrm{w}}$ by the following formula

$$
\mathrm{I}_{\mathrm{W}}=\beta_{\mathrm{f}}\left(1-\beta_{\mathrm{f}}\right) \mathrm{I}_{\mathrm{Z}} \mathrm{h}_{\mathrm{S}}{ }^{2}
$$

where $h_{s}$ is the distance between the shear centres of the flanges.

Using eqn (8) and $z_{j}$ calculated by eqn (9) $)_{2}$ the correct values of $M_{K I}$ were obtained. Also, the approximate formula for $\mathrm{z}_{\mathrm{j}}$ was proposed in Annex $\mathrm{F}$ of Euro Code 3 ,

$$
\begin{array}{ll}
\text { for } \beta_{\mathrm{f}}>0.5 & \mathrm{z}_{\mathrm{j}}=0.8\left(2 \beta_{\mathrm{f}}-1\right) \mathrm{h}_{\mathrm{s}} / 2 \\
\text { for } \beta_{\mathrm{f}}<0.5 & \mathrm{z}_{\mathrm{j}}=1.0\left(2 \beta_{\mathrm{f}}-1\right) \mathrm{h}_{\mathrm{s}} / 2
\end{array}
$$

Now using equation (8) and an approximate equation for $z_{j}$ (11) or (12) the approximate values of elastic critical moment $\mathrm{M}_{\mathrm{KI}}$ were obtained. It should be mentioned that the relation between the previously explained monosymmetry parameter $r_{z}$ (eqn (4)) and $z_{j}$ is $r_{z}=2 z_{j}$. For all examined load cases the coefficients $\mathrm{k}=\mathrm{k}_{\mathrm{W}}=1.0$.

\subsection{Parametric investigation}

In the following the obtained results of the elastic critical moment for lateral torsional buckling $\mathrm{M}_{\mathrm{KI}}$ calculated by the previously explained approaches will be presented:

- EC3 (correct formulae),

- $\quad$ EC3 (approximate formulae)

considering monosymmetric I-cross-sections with the following values of the monosymmetry degree $\beta_{\mathrm{f}}=0 ; 0.1 ; 0.2 ; 0.3 ; 0.4 ; 0.5 ; 0.6 ; 0.7 ; 0.8 ; 0.9 ; 1.0$.

Investigation was carried out on 9 cross-sections based on the following: IPB (HEA)140， IPB 1 (HEA)500， IPB 1 (HEA)900，IPB(HEB)140， IPB(HEB)500, IPB(HEB)900, IPE120, IPE330 and IPE550, but for each of these cross-sections investigation was carried out for eleven values of the monosymmetry degree $\beta_{\mathrm{f}}$, see Figure 6 . For $\beta_{\mathrm{f}}=0.5$ the cross section actually have dimensions of HEA 500; for $\beta_{\mathrm{f}}=0$ it is an inverted T-cross sections with dimensions of the web and the flange as of HEA 500. For the wanted values of $\beta_{\mathrm{f}}$ and for fixed dimensions of one flange it is easy to calculate the dimensions of the other flange.

To obtain the cross-section properties $\left(\mathrm{I}_{\mathrm{z}}, \mathrm{I}_{\mathrm{t}}, \mathrm{I}_{\mathrm{w}}\right.$, etc.), FEM software RUBSTAHL-KSTAB 2000 is used (Kindmann [7]). For each cross-section, investigations were done for loads applied at the top flange, shear centre and bottom flange, respectively, for each value of beam parameter, $\bar{K}(\bar{K}=0.1 ; 0.5$; $1.0 ; 1.5 ; 2.0$ and 2.5 ) and for each degree of monosymmetry $\beta_{\mathrm{f}}$. All this was done for the two earlier explained load cases. 
To enable a comparison of results between monosymmetric I-cross sections with different degrees of monosymmetry, $\beta_{\mathrm{f}}$ it was necessary to calculate the dimensionless elastic critical moment

$$
\mathrm{M}_{\mathrm{KI}}[-]=\frac{\mathrm{M}_{\mathrm{KI}}[\mathrm{kNm}] \cdot \mathrm{L}}{\sqrt{\mathrm{EI}_{\mathrm{Z}} \mathrm{GI}_{\mathrm{t}}}}
$$

Considering the topic of load-carrying capacity for lateral torsional buckling of monosymmetric I-cross-sections, the following investigations have been done:

- $\quad$ influence of monosymmetry degree, $\beta_{\mathrm{f}}$ to lateral torsional capacity, $\mathrm{M}_{\mathrm{KI}}$ for different values of beam parameter, $\overline{\mathrm{K}}$ (which means for different beam length),

- deviations [\%] of $r_{z}$ obtained by the approximate formulas (EC3 and Kitipornchai and Trahair formulae) from the correct formulae given by EC3.

The results are given below.

\section{Numerical results}

For the central concentrated load case for all examined cross sections and a load applied at the top flange, shear centre and bottom flange it was found that the best capacities have highly monosymmetric cross sections with $\beta_{\mathrm{f}}=1.0$ and 0.9 . For the uniformly distributed load case, opposite to the previous load case where the distribution is smooth, the additional influence of beam parameter $\overline{\mathrm{K}}$ has been noticed. Here, when the load is applied at the top flange, and $\overline{\mathrm{K}} \geq 1.5$ the best capacities have cross sections with $\beta_{\mathrm{f}}=0.9 ; 0.8 ; 1.0$, respectively. But for $\overline{\mathrm{K}}<1.5$, as well as in the case when the load is applied at the bottom flange, load capacity is distributed smoothly and the best capacities have cross sections with $\beta_{\mathrm{f}}=1.0$. When the load is applied at the shear centre the behaviour of the cross section concerning the lateral torsional buckling is different: for $\overline{\mathrm{K}} \geq 1.0$ the best capacities have cross sections with $\beta_{\mathrm{f}}=0.8$ followed by 0.7 and 0.9 . It is interesting to mention that for shear centre loading and for $\overline{\mathrm{K}}>1.5$ even the double symmetric cross section $\left(\beta_{\mathrm{f}}=0.5\right)$ has greater capacity than the T-beam $\left(\beta_{\mathrm{f}}\right.$ $=1.0$ ). Figure 7 shows elastic critical loads, $\mathrm{M}_{\mathrm{KI}}$, of monosymmetric I beams under central concentrated load applied at top flange, shear centre and bottom flange. Figure 9 shows $\mathrm{M}_{\mathrm{KI}}$ of the monosymmetric I beams under uniformly distributed load applied at the top flange, shear centre and bottom flange.

The Kitipornchai and Trahair approximate formulae for calculation of $r_{z}$ are reported to be of good accuracy in a range between $0.1 \leq \beta_{\mathrm{f}} \leq 0.9$ (deviation from correct formulae up to $6 \%$ ). In the case of highly monosymmetric cross sections for which $\beta_{\mathrm{f}}$ approaches 0 or 1,0 the deviation is up to $18 \%$, as opposed to the EC3 approximate formulae for which the deviation is up to $50 \%$, Figure 8 . 
124 Computational Methods and Experimental Measurements XIII
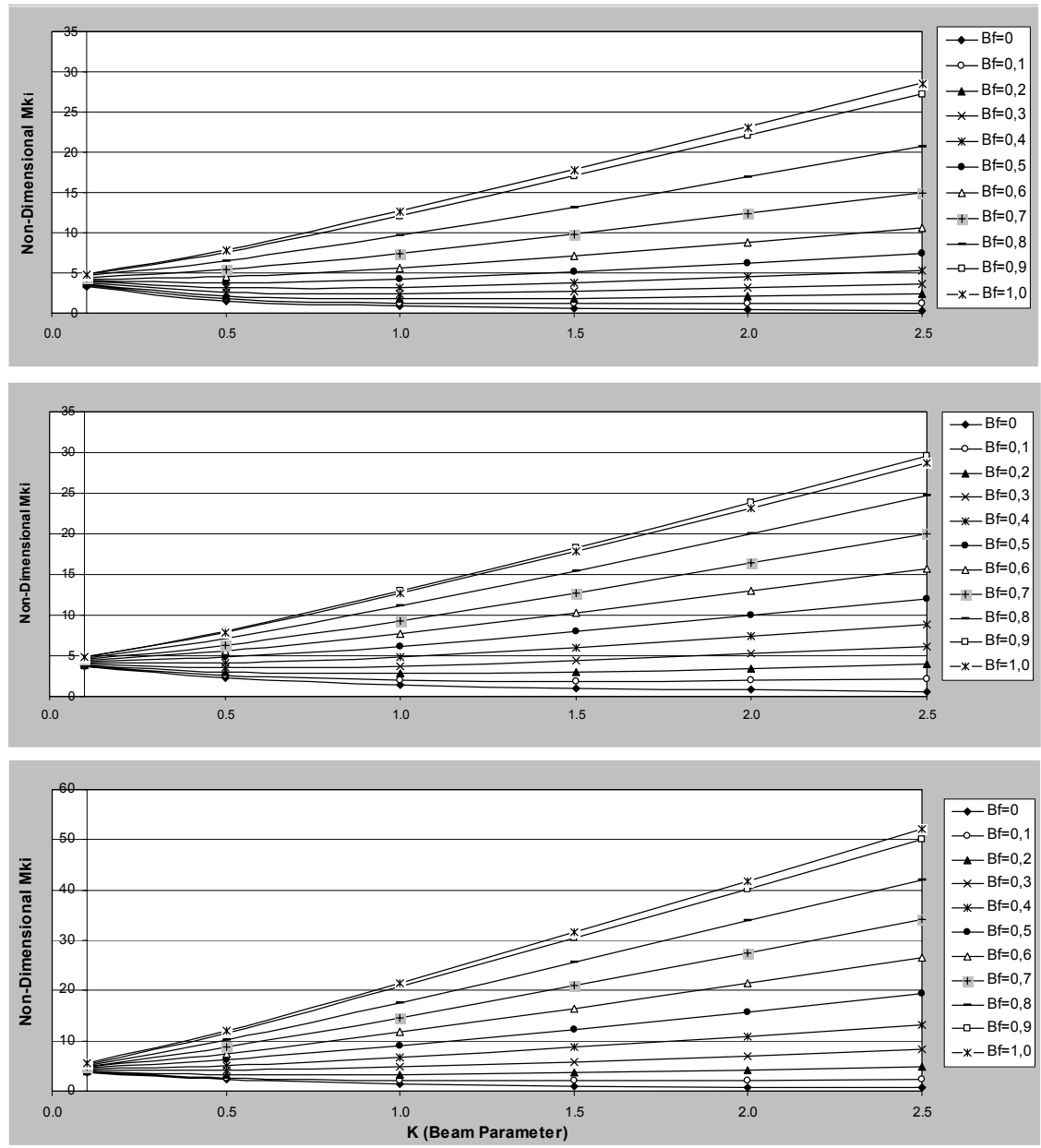

Figure 7: Central concentrated load.

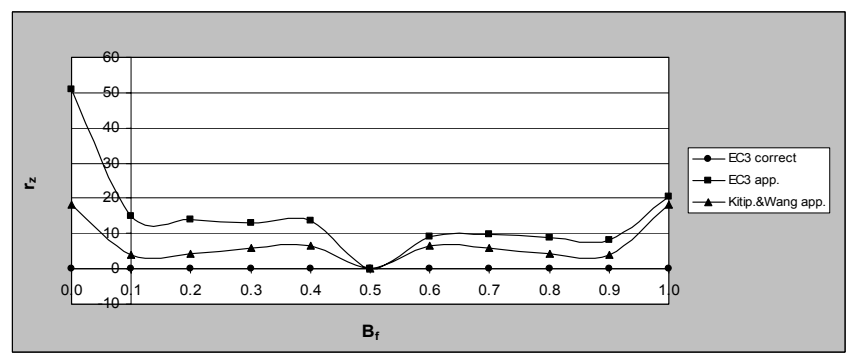

Figure 8: Deviations [\%] of $\mathrm{r}_{\mathrm{z}}$. 

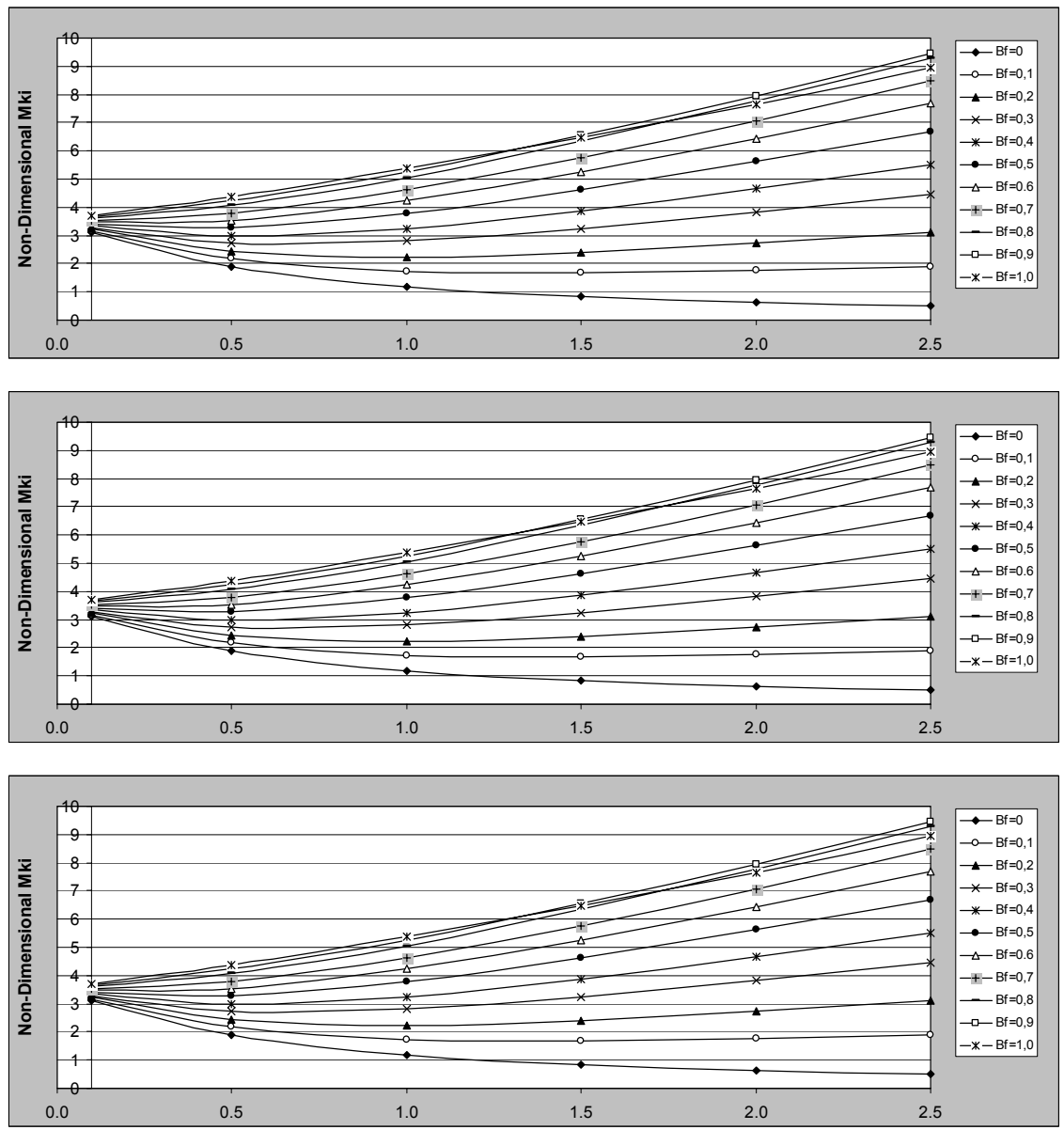

Figure 9: Uniformly distributed load.

\section{Conclusions}

Influence of the monosymmetric cross section shape on lateral torsional buckling capacity has been investigated in this paper.

These results based on EC3, where it was found that the best capacities have cross sections with $\beta_{\mathrm{f}}=1.0(0.9)$, are different in comparison with previously investigated approaches of RUBSTAHL-KSTAB 2000 (Djurić [1]) and Kitipornchai and Trahair (Kitipornchai and Trahair [4]) where for the same load cases the capacity of the T-beam is much lower then for beams with $\beta_{\mathrm{f}}=0.9$ and 0.7 . 
Also it was found that the approximate formulae for the monosymmetry parameter $r_{z}$ given by Kitipornchai and Trahair is more accurate in comparison to the $r_{z}$ correct formulae than the EC3 approximation formulae.

After this extensive theoretical and numerical research, it appears necessary to experimentally verify these approaches in order to determine which is the most accurate in describing the behaviour of real models. Using the approximation in respect to the accurate formula for calculation of $r_{z}$, the calculation time would be significantly shortened, which would be very important for the design of demanding structures. It has been theoretically demonstrated that certain monosymmetric I cross sections possess higher bearing capacity to lateral torsional buckling than the double symmetrical I cross sections. Using the monosymmetric cross sections, considerable savings could be accomplished, and the steel structure weight would be reduced. This is very important for contemporary engineering practice.

Experimental investigation is a present occupation of the authors.

\section{Acknowledgement}

The support from the Ministry of Science and Environmental Protection, Republic of Serbia, through the projects ON144002 and ON144027 is gratefully acknowledged.

\section{References}

[1] Djurić D., Influence of the Cross-Section-Shape on the Bifurcation-Loads of Bending Girders, Master thesis, Ruhr University Bochum, Germany, 2002.

[2] Trahair, N.S., Flexural-Torsional Buckling of Structures, $1^{\text {st }}$ edn, E\&FN Spon (Chapman \& Hall) London, 1993.

[3] Galambos T.V. Guide to Stability Design Criteria for Metal Structures. $4^{\text {th }}$ edn, John Wiley and Sons, New York, 1988.

[4] Kitipornchai, S. and Trahair, N.S. Buckling properties of monosymmetric I-beams. Journal of the Structural Division, ASCE, 106 (941-57), 1980.

[5] Anderson, J.M. and Trahair N.S. Stability of monosymmetric I-beams and cantilevers. Journal of Structural Division, ASCE, 98 (269-86), 1972

[6] Wang, C.M. and Kitipornchai, S. Buckling capacities of monosymmetric Ibeams. Journal of Structural Engineering, ASCE 112 (2373-91), 1986.

[7] R. Kindmann, Computed-oriented Design of Steel Structures. RuhrUniversity, Bochum, 2001. 